\title{
Ethanol-Sensitive Pacemaker Neurons in the Mouse External Globus Pallidus
}

\author{
Karina P Abrahao', Jessica H Chancey', C Savio Chan² and David M Lovinger,, \\ 'Laboratory for Integrative Neuroscience, Division of Intramural Clinical and Biological Research, National Institute on Alcohol Abuse and \\ Alcoholism, National Institutes of Health, Bethesda, MD, USA; ${ }^{2}$ Department of Physiology, Feinberg School of Medicine, Northwestern University, \\ Chicago, IL, USA
}

\begin{abstract}
Although ethanol is one of the most widely used drugs, we still lack a full understanding of which neuronal subtypes are affected by this drug. Pacemaker neurons exert powerful control over brain circuit function, but little is known about ethanol effects on these types of neurons. Neurons in the external globus pallidus (GPe) generate pacemaker activity that controls basal ganglia, circuitry associated with habitual and compulsive drug use. We performed patch-clamp recordings from GPe neurons and found that bath application of ethanol dose-dependently decreased the firing rate of low-frequency GPe neurons, but did not alter the firing of high-frequency neurons. GABA or glutamate receptor antagonists did not block the ethanol effect. The GPe is comprised of a heterogeneous population of neurons. We used Lh×6-EGFP and NpasI-tdTm mice strains to identify low-frequency neurons. Lh×6 and Npas I neurons exhibited decreased firing with ethanol, but only Npas I neurons were sensitive to $10 \mathrm{mM}$ ethanol. Large-conductance voltage and $\mathrm{Ca}^{2+}$-activated $\mathrm{K}^{+}$(BK) channel have a key role in the ethanol effect on GPe neurons, as the application of BK channel inhibitors blocked the ethanol-induced firing decrease. Ethanol also increased BK channel open probability measured in single-channel recordings from NpasI-tdTm neurons. In addition, in vivo electrophysiological recordings from GPe showed that ethanol decreased the firing of a large subset of low-frequency neurons. These findings indicate how selectivity of ethanol effects on pacemaker neurons can occur, and enhance our understanding of the mechanisms contributing to acute ethanol effects on the basal ganglia.

Neuropsychopharmacology (2017) 42, 1070-108I; doi:I0.1038/npp.2016.25I; published online I4 December 2016
\end{abstract}

\section{INTRODUCTION}

Ethanol is one of the most widely used drugs. An estimated $4.9 \%$ of the world's adult population suffers from alcohol use disorder (Gowing et al, 2015). Despite this devastating statistic, we still lack a good understanding of how brain regions and neuronal subtypes are affected by ethanol. The majority of neuropharmacological studies do not differentiate neuronal subpopulations, even though there are data suggesting that ethanol effects may be restricted to specific subsets of neurons (Yang et al, 2000). It is generally thought that ethanol is a nonspecific pharmacological agent given its small molecular size and amphipathic characteristics. However, studies have shown that ethanol has relatively few known primary molecular targets (Vengeliene et al, 2008). Thus, it is reasonable to speculate that the pattern of expression of these targets determines if a neuronal subpopulation will be affected by ethanol.

*Correspondence: Dr DM Lovinger, Laboratory for Integrative Neuroscience, Division of Intramural Clinical and Biological Research, National Institute on Alcohol Abuse and Alcoholism, National Institutes of Health, Bethesda, MD 20892, USA. Tel: 30I 443 2445, Fax: 301480 8035, E-mail: lovindav@mail.nih.gov

Received 8 March 2016; revised 26 October 2016; accepted 27 October 2016; accepted article preview online 9 November 2016
The basal ganglia are implicated in several behavioral effects of drugs of abuse, including the progression from hedonic to habitual and compulsive drug use (Everitt and Robbins, 2005). The majority of ethanol pharmacological studies have been focused on basal ganglia synaptic transmission (Lovinger and Roberto, 2013). However, a number of neurons in the basal ganglia, such as those in the globus pallidus (GP), are spontaneously active. The GP can be subdivided into internal and external (GPe) parts. Although the GPe was historically viewed as a relay station of the striatal indirect pathway with a specific role in movement control (Hegeman et al, 2016), new studies have shown GPe involvement in cognition, learning and sleep (Adler et al, 2012; Arkadir et al, 2004; Gdowski et al, 2001; Qiu et al, 2016; Qiu et al, 2014; Schroll et al, 2015).

Few studies have focused on ethanol effects on pacemaker neurons. A neuroimaging study in humans revealed ethanolinduced decreases in GPe activity (Nikolaou et al, 2013). It is possible that this effect is specific to a subpopulation of neurons as it enhances the inhibitory action of GABA at some, but not all, neurons in the rat GPe (Criswell et al, 1995). The GPe was considered to have uniform cellular constituents for many years (Albin et al, 1989; DeLong, 1990; Smith et al, 1998), but recent work has shown that the GPe is actually comprised of multiple subtypes of neurons. There are a number of cellular markers and electrophysiological 
properties that can help to differentiate GPe neuronal populations (Hegeman et al, 2016) and characterize specific effects of ethanol.

In this study, we characterized ethanol-sensitive neurons in the mouse GPe and the mechanism by which ethanol affects these neurons. We show that ethanol decreases the firing rate of a specific population of GPe neurons characterized by low basal firing rates using in vitro and in vivo electrophysiological recordings from wild-type mice. In addition, transgenic mice were used to identify lowfrequency ethanol-sensitive neurons in vitro. We also provide evidence of a role for the large-conductance voltage and $\mathrm{Ca}^{2+}$-activated $\mathrm{K}^{+}(\mathrm{BK})$ channel in this ethanol action, including ethanol potentiation of channel function.

\section{MATERIALS AND METHODS}

\section{Animals}

All procedures used in this study were performed in agreement with the National Institutes of Health Guide to the Care and Use of Laboratory Animals and with approval of the National Institute on Alcohol Abuse and Alcoholism Animal Care and Use Committee. Male C57BL/6J mice (Jackson Laboratory, Bar Harbor, ME) were used as 'wildtype' animals. To target low-frequency firing neurons in the GPe, we used male and female hemizygous $\operatorname{Tg}$ (Lhx6-EGFP) BP221Gsat BAC (Lhx6-EGFP, provided by Dr Aryn Gittis, GENSAT) or Npas1-Cre-2A-tdTomato BAC mice (Npas1tdTm, Hernandez et al, 2015). All mice were housed in groups of two to four on a $12 \mathrm{~h}$ light cycle (lights on at $06: 30 \mathrm{~h}$ ) with ad libitum access to food and water.

\section{In Vitro Electrophysiology}

Whole-cell patch-clamp recordings. Mouse coronal GPe slices $(250-300 \mu \mathrm{m})$ were prepared using a Leica VT1200S Vibratome (Leica Microsystems, Buffalo Grove, IL). PN21-PN58 mice were anesthetized with isoflurane, decapitated, and the brain was quickly removed and immersed in ice-cold sucrose cutting solution containing the following (in mM): 194 sucrose, $30 \mathrm{NaCl}, 4.5 \mathrm{KCl}, 26 \mathrm{NaHCO}_{3}, 1.2$ $\mathrm{NaH}_{2} \mathrm{PO}_{4}, 10$ D-glucose, $1 \mathrm{MgCl}_{2}$, and saturated with $95 \%$ $\mathrm{O}_{2} / 5 \% \mathrm{CO}_{2}$. Slices were equilibrated for $30-40 \mathrm{~min}$ at $32^{\circ} \mathrm{C}$ in carbogen-bubbled artificial cerebrospinal fluid (aCSF) containing the following (in $\mathrm{mM}$ ): $124 \mathrm{NaCl}, 4.5 \mathrm{KCl}, 26$ $\mathrm{NaHCO}_{3}, 1.2 \mathrm{NaH}_{2} \mathrm{PO}_{4}, 10$ D-glucose, $1 \mathrm{MgCl}_{2}$, and $2 \mathrm{CaCl}_{2}$. Slices were then incubated in room temperature until transferred to the recording chamber.

Recordings from GPe neurons were performed at $30-32{ }^{\circ} \mathrm{C}$ with a $\sim 2 \mathrm{ml} / \mathrm{min}$ aCSF flow rate, using micropipettes (2-4 M $\Omega$ ) made from $1.5 \mathrm{~mm}$ OD/1.12 mm ID borosilicate glass with a filament (Worlds Precision Instruments, Sarasota, FL) pulled with a P-97 Sutter Instruments (Novato, CA) puller. Neurons were visualized using an upright microscope (Scientifica, Uckfield, East Sussex, UK) with a LUMPlanFL $\mathrm{N} \times 40 / 0.80 \mathrm{~W}$ objective (Olympus, Waltham, MA). Recording pipettes were filled with an internal solution containing the following (in $\mathrm{mM}$ ): $140 \mathrm{~K}$-gluconate, $10 \mathrm{HEPES}, 0.1 \mathrm{CaCl}_{2}, 2 \mathrm{MgCl}_{2}, 1 \mathrm{EGTA}$, 2 ATP-Mg, and 0.2 GTP-Na, pH 7.25 (300-305 mOsm). When recording in slices from wild-type $\mathrm{C} 57 \mathrm{BL} / 6 \mathrm{~J}$ mice,
1\% Neurobiotin (Vector Laboratories, Burlingame, CA) was added into the internal solution for post hoc immunocytochemistry and confocal imaging. Recordings were obtained using a Multiclamp 700A amplifier, Digidata 1322A digitizer and analyzed using pClamp 10.3 software (Molecular Devices, Sunnyvale, CA). A low-pass filter of $2 \mathrm{kHz}$ and sampling frequency of $10 \mathrm{kHz}$ were used.

Neurons were recorded for $5 \mathrm{~min}$ in whole-cell currentclamp $(I=0)$ gap-free mode to allow stabilization of firing rate. Neurons presenting unstable or no spontaneous firing were excluded from the experiment. To further characterize the electrophysiological properties of the neurons (Supplementary Table S1), a negative current step $(-200 \mathrm{pA}, 1000 \mathrm{~ms})$ was applied. The next $5 \mathrm{~min}$ of recording was used as the baseline, followed by bath application of ethanol for $5 \mathrm{~min}$. Then, a 5-10 min washout was performed. A current step protocol was applied during the last minute of ethanol application and after washout in the first experiment.

To analyze the contribution of $\mathrm{GABA}_{\mathrm{A}}$ receptors, glutamatergic AMPA+NMDA ionotropic receptors, or $\mathrm{BK}$ channels, ethanol effects were examined in the presence of $20 \mu \mathrm{M}$ bicuculline ((-)-bicuculline methiodide, Cat. 32503, Tocris Bioscience, Avonmouth, Bristol, UK), $10 \mu \mathrm{M}$ DNQX (DNQX disodium salt, Cat. 2312, Tocris Bioscience) $+50 \mu \mathrm{M}$ AP5 (DL-AP5 sodium salt, ab120271, Abcam, Cambridge, MA), $500 \mathrm{nM}$ penitrem-A (diluted from $10 \mathrm{mM}$ penitrem-A in DMSO, Cat. 4617, Tocris Bioscience) or $1 \mu \mathrm{M}$ paxilline (diluted from $10 \mathrm{mM}$ paxilline in DMSO, Cat. 2006, Tocris Bioscience), respectively. In experiments using C57BL/6J mice, antagonists were applied after the first 5 min of firing recording.

Cell-attached single-channel recordings. Recordings were performed in brain slices prepared as previously described, at room temperature with a $\sim 1.5 \mathrm{ml} / \mathrm{min}$ aCSF flow rate, using micropipettes (1-2 M $\Omega$ ) pulled from $1.5 \mathrm{~mm} \mathrm{OD} / 0.84 \mathrm{~mm}$ ID borosilicate glass with a filament (World Precision Instruments). Recording pipettes were filled with aCSF. Tetrodotoxin citrate (TTX, $500 \mathrm{nM}$, HelloBio, Bristol, UK) was present during these recordings to eliminate any contamination from sodium channels. Bicuculline $(20 \mu \mathrm{M})$, DNQX $(10 \mu \mathrm{M})$, and AP5 $(50 \mu \mathrm{M})$ were present to block synaptic transmission. Neurons were visualized and cellattached recordings were obtained as described previously. A low-pass filter of $1.4 \mathrm{kHz}$ and sampling frequency of $4 \mathrm{kHz}$ were used.

Single-channel currents were recorded using the Giga-seal cell-attached configuration (average seal resistance $=$ 4-10 Gohm). The patch potential was held in voltage clamp at $-120 \mathrm{mV}$. In this recording configuration, BK channel openings were observed as downward deflections (current flowing into the pipette), and we represent them as such. Recordings were performed in gap-free mode. Baseline channel events were recorded before any drug application. In some slices, $\mathrm{BK}$ inhibitors $(3 \mu \mathrm{M}$ penitrem-A or $3 \mu \mathrm{M}$ paxilline) were applied followed by $40 \mathrm{mM}$ ethanol and other slices, ethanol was applied before the BK inhibitors.

\section{Immunohistochemistry}

Brain BLAQ staining. Slices with neurobiotin-filled neurons were fixed overnight in $4 \%$ formaldehyde in PBS. 
Fixation was initially at room temperature and, after $2 \mathrm{~h}$, sections were transferred to $4{ }^{\circ} \mathrm{C}$ for $12-24 \mathrm{~h}$. Slices were subjected to 'Brain BLAQ' (Block Lipids and Aldehyde Quench), to rapidly reduce autofluorescence in thick brain sections, as described previously by Kupferschmidt et al (2015). Slices were blocked using 5\% BSA in PBST for $4 \mathrm{~h}$, and incubated for $72 \mathrm{~h}$ at $4{ }^{\circ} \mathrm{C}$ in the primary antibody rabbit anti-PV (1 : 1000 dilution; PV27, Swant, Marly, Switzerland). Following four washes in PBST over 16-24h, slices were incubated for $48 \mathrm{~h}$ at $4{ }^{\circ} \mathrm{C}$ in the following secondary antibody: 568 goat anti-rabbit (1:1000 dilution; 01102, Life Technologies, Carlsbad, CA) and Streptavidin, AlexaFluor488 conjugate (1:1000 dilution; S11223, Life Technologies). Slices were then washed four times in PBST over 16-24 h, and washed for $1 \mathrm{~h}$ in PBS before storage.

Confocal imaging. Sections were mounted in Vectashield (Vector Laboratories, Burlingame, CA) and imaged on a Zeiss 510 Meta confocal scan head mounted on a Zeiss Z1Axio Observer inverted microscope frame (Zeiss, Oberkochen, Germany). Appropriate sets of filter cubes were used to image the fluorescence channels: FITC filter for the AlexaFluor-488 (excitation 450-490 nm, dichroic 495, emission 500-550 nm) and Rhodamine filter for the 568 goat anti-rabbit antibody (excitation 532-558nm, dichroic 565, emission 570-640 nm). Images were taken using Zeiss PlnApo $\times 20 / 0.8$ DICII and CApo $\times 40 / 1.2 \mathrm{~W}$ DICIII (water-immersion solution: Immersol W, Zeiss) objectives. $Z$-stacks images ( $2 \mu \mathrm{m}$ thick, $2 \mu \mathrm{m}$ pinhole) were acquired to analyze co-localization.

\section{In Vivo Electrophysiology}

Electrode implantation. Four male C57BL/6J (PN60PN73) mice were unilaterally implanted with tungsten electrode micro-arrays in either a 32 electrode $(35 \mu \mathrm{m}$ diameter; $150 \mu \mathrm{m}$ electrode spacing) fixed design or a 16 electrode $(23 \mu \mathrm{m}$ diameter $)$ movable micro-bundle design (Innovative Neurophysiology, Inc., Durham, NC), with a silver ground wire. Mice were anesthetized with 5\% isoflurane, placed in the stereotax, the scalp opened and the skull was cleaned with hydrogen peroxide. The ground wires were attached to two stainless steel screws implanted supradurally in the skull. A cranial window was made centered at $-0.5 \mathrm{~mm} \mathrm{AP}$ and $\pm 2.0 \mathrm{~mm} \mathrm{ML}$ from bregma for fixed or $-0.4 \mathrm{~mm} \mathrm{AP}$ and $\pm 2.2 \mathrm{~mm} \mathrm{ML}$ for drivable implants. Fixed-electrode arrays were rotated $45^{\circ}$ medially, such that the anterior portion of the electrode was more medial. Electrodes were then lowered vertically $3.6-3.7 \mathrm{~mm}$ from the brain surface, with the final depth determined by online monitoring of neural activity. Drivable arrays were lowered $3 \mathrm{~mm}$ from brain surface, then electrodes were advanced to a final depth of $3.4-3.8 \mathrm{~mm}$. Final electrode depths were set based on the observation of spontaneous unit firing greater than $2 \mathrm{~Hz}$. The electrodes were secured with a cold-cure dental acrylic head cap. Mice were given ketoprofen $(5 \mathrm{mg} / \mathrm{kg}$, intraperitoneal (i.p.)) and fluids for 2 days post surgery and were allowed to recover for 3 weeks.

Testing. Mice were given a habituation session 3 days before testing in which they were briefly anesthetized with isoflurane and connected to a 32-channel headstage, and then placed into a novel open field chamber $(40 \mathrm{~cm} \times 40 \mathrm{~cm}$ square). Mice were given a saline i.p. injection (' $10^{-2}$ of weight' $\mathrm{ml}$ ) and allowed to habituate to the chamber for $2 \mathrm{~h}$, while units were sorted using an online-sorting algorithm (Sort Client, Plexon Inc., Dallas, TX). On testing days, mice were again briefly anesthetized to be connected to the headstage, and then were placed in the open field chamber for $1 \mathrm{~h}$ to recover, and units were monitored online. After the hour recovery session, spike data and locomotor behavior were recorded for $3 \mathrm{~h}$. Mice were given i.p. injections at the 1- and 2-h time points receiving saline at 1-h time point and $1 \mathrm{~g} / \mathrm{kg}$ ethanol at the other in a counterbalanced design. Unit activity was collected using the MAP system (Plexon Inc.) at a digitization rate of $40 \mathrm{kHz}$ with 12 -bit resolution. A lowpass filter of $250 \mathrm{~Hz}, 2$-pole was used. Locomotion activity was videotaped and analyzed with the Ethovision system (Noldus, Leesburg, VA).

Histology. Mice were transcardially perfused with PBS followed by $4 \%$ formaldehyde and brains were removed and kept in $4 \%$ formaldehyde overnight. The brains were maintained in PBS until sliced with a Pelco easiSlicer vibratome (Ted Pella Inc., Redding, CA) in $50 \mu \mathrm{m}$ slices. Slices were blocked with $4 \%$ BSA for $4 \mathrm{~h}$ in room temperature and incubated overnight at $4{ }^{\circ} \mathrm{C}$ in propidium iodide ( $1: 1000$, Molecular Probes, Eugene, OR). Next, slices were washed four times with PBST for $1 \mathrm{~h}$ each. DAPI $(1: 20000$; Invitrogen, Carlsbad, CA) was added in the first wash. Slices were washed with PBS before mounting. Pictures were taken with an AxioZoom.V10 (Zeiss) microscope.

\section{Data Analysis}

The in vitro electrophysiological data were obtained using ClampFit 10.3. Statistical analysis was performed in ClampFit 10.3, STATISTICA 12 (Dell software, Round Rock, TX) and Microsoft Office Excel software (Microsoft, Redmond, WA). Statistical significance for within-cell firing comparisons was evaluated using one-way repeated measure ANOVAs for the time-course data set and/or bar graphs of the average firing of baseline, ethanol, and wash conditions (marked as 1, 2, and 3, respectively, represented in the timecourse graphs). ANOVAs were followed by Fisher's post hoc tests for least-significant difference in multiple comparisons.

The single-channel events as well as open and closed dwell times were obtained with the single-channel search event detection routines in ClampFit 10.3 software after adjusting baseline to zero. A threshold of at least $-10 \mathrm{pA}$ was set as the first open level. Two minutes of recording were used for each experimental condition. Open probability $\left(\mathrm{NP}_{\mathrm{o}}\right)$ was calculated with the event analyses routine in the ClampFit 10.3 software. Open probability was calculated for each patch as $\mathrm{NP}_{\mathrm{o}}$, where $N$ represents the number of channels in the patch (one to three in our patches). The $\mathrm{P}_{\mathrm{o}}$ is calculated as $\left(T_{\mathrm{o}}\right) /\left(T_{\mathrm{o}}+T_{\mathrm{c}}\right)$, where $T_{\mathrm{o}}$ equals total open time over the recording time and $T_{\mathrm{c}}$ equals total closed time during that period. Averages of $2 \mathrm{~min}$ for each experimental condition were compared by Student's $t$-test for dependent samples with STATISTICA software.

Spike data from in vivo recording experiments were resorted offline with Offline Sorter (Plexon Inc.) using 
a
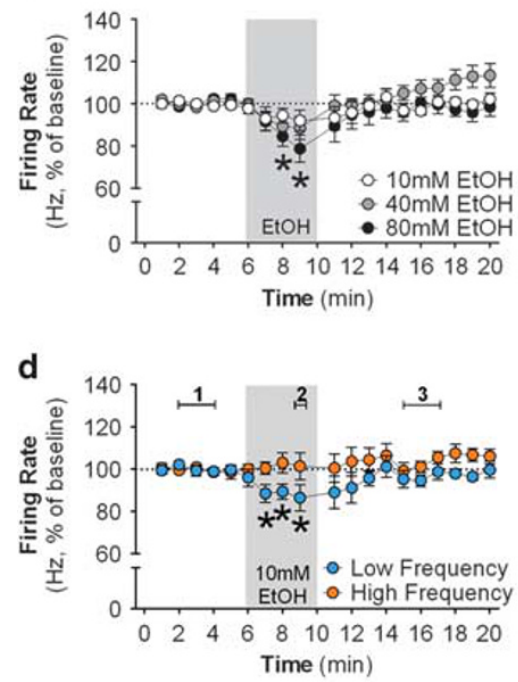

b

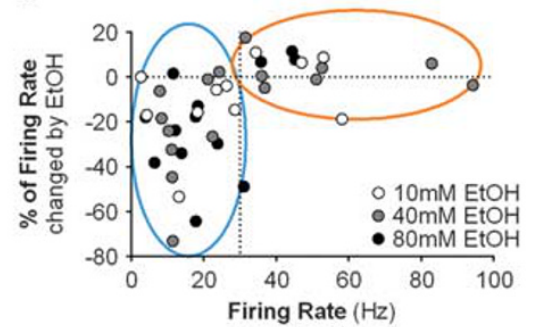

C

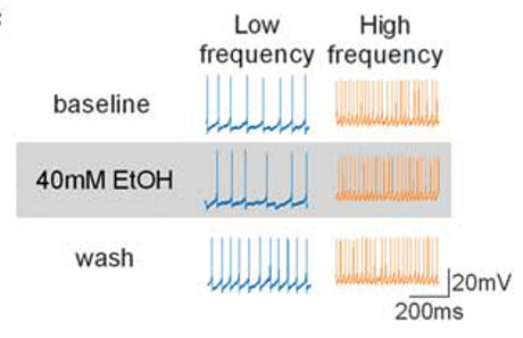

e

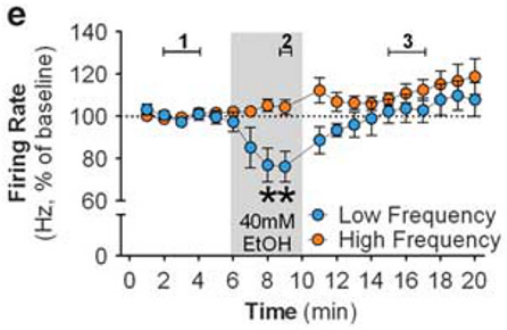

f

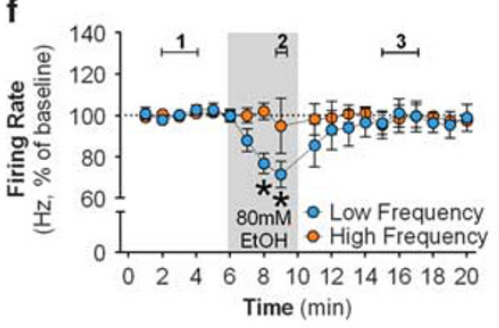

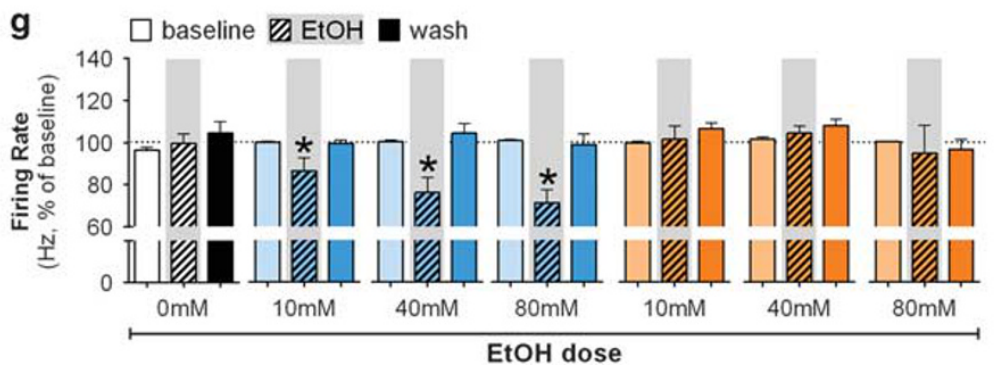

Figure I Ethanol decreases the firing rate of GPe low-frequency neurons in vitro. (a) Time-course graph of the firing rate of all GPe neurons recorded before, during, and after bath application of $10 \mathrm{mM}$ ethanol $\left(n=11\right.$ neurons from 8 mice), $40 \mathrm{mM}$ ethanol $\left(n=16\right.$ neurons from 10 mice, $F_{(18,270)}=3.45$, $p<0.05$, post hoc test indicates lower firing rate in minutes 8-9 when compared with minutes $1-2$ ), or $80 \mathrm{mM}$ ethanol ( $n=13$ neurons from 7 mice, $F_{(18,2 \mid 6)}=2.88, p<0.05$, post hoc test indicates lower firing rate in minutes 8-9 when compared with minutes $\left.1-5\right)$. Bath application of 40 and 80 mM ethanol slightly decreased the firing rate of GPe neurons ( $* 0<0.05$, different from baseline and washout time points). (b) Scatterplot of the percent change in firing rate induced by 10,40 , and $80 \mathrm{mM}$ ethanol versus the baseline firing rate of individual neurons. Low-frequency neurons are circled in blue $(<30 \mathrm{~Hz})$ and high frequency in orange $(>30 \mathrm{~Hz}$ ). Note that ethanol decreased the firing rate of low-frequency neurons but not high-frequency neurons. (c) Representative traces of low- and high-frequency neurons during baseline, $40 \mathrm{mM}$ ethanol and washout. ( $\mathrm{d}-\mathrm{f}$ ) Time course of firing rate of low-frequency (blue circles) and high-frequency neurons (orange circles) during the application of $10 \mathrm{mM}$ ethanol (low frequency: $n=7$ neurons from 7 mice, $F_{(18,108)}=1.81$, * $p<0.05$, post hoc test indicates lower firing rate in minutes 7-9 when compared with minutes I-5 and minutes 14 and 20; high frequency: $n=4$ neurons from 4 mice: $\left.F_{(18,54)}=1.18\right), 40 \mathrm{mM}$ ethanol (low frequency: $n=9$ neurons from 7 mice, $F_{(18,144)}=2.71$, $* 2<0.05$, post hoc test indicates lower firing rate in minutes $8-9$ when compared with minutes $1-5$ and $12-20$; high frequency: $n=7$ neurons from five mice, $F_{(18,108)}=2.83, p<0.05$, post hoc test indicates higher firing rate in minutes 17-20 when compared with minutes I-5), and $80 \mathrm{mM}$ ethanol (low frequency: $n=9$ neurons from six mice, $F_{(18,144)}=3.43$, * $p<0.05$, post hoc test indicates lower firing rate in minutes 8-9 when compared with minutes $I-5$ and minutes 12-20; high frequency: $n=4$ neurons from 4 mice, $\left.F_{(18,54)}=0.52\right)$, respectively. Note that application of ethanol decreases the firing of low-frequency neurons ( $P<0.05$, different from baseline and washout). The fifth data point during ethanol application is missing because that minute was used for a current step protocol experiment (Supplementary Figure SI). (g) Summary bar graph of firing rate of GPe neurons during baseline, ethanol, and washout calculated as average from time segments I, 2, and 3 indicated in time-course graphs. Ethanol was able to induce a dose-dependent decrease of the firing rate of low-frequency neurons, but did not change the firing rate of high-frequency neurons even at the highest dose. Firing rate in time courses and bar graphs are represented as percentage of baseline levels. All error bars represent SEM.

principal component analysis to isolate single units, determined by multivariate ANOVA in 3D cluster space, and pairwise 3D single unit comparisons. All outliers were removed using $a \pm 3 \mathrm{SD}$ threshold. Only single units that were stable throughout the $3-\mathrm{h}$ recording session were used in further analysis. Firing rates were analyzed in NeuroExplorer software (Nex Technologies, Madison, AL) as instantaneous frequency in bins of $30 \mathrm{~s}$. Baseline firing rate was calculated as the average firing during the 1-h period before injections. Firing rate was transformed to $\%$ of baseline (10 min of recording before each i.p. administration). Comparison between saline- and ethanol-induced changes in firing was done by calculating the \% change in firing induced by ethanol compared with saline over the first $5 \mathrm{~min}$ after i.p. injections. A simple sample $t$-test against 0 was run for the low- and high-frequency units. We considered that firing rate was altered by ethanol if there was at least a change of $-10 \%$ of the firing when compared with the firing after saline. This cutoff was based on the $10 \mathrm{mM}$ ethanol-induced change in firing in the in vitro experiments.

Number of neurons and mice used for each experiment are described in the figure legends. Data are shown as mean \pm SEM. Differences were considered statistically significant at $p<0.05$. 
a

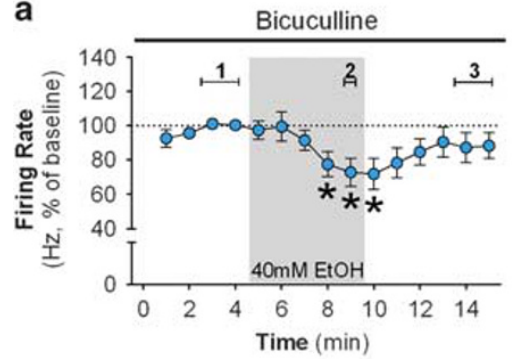

b

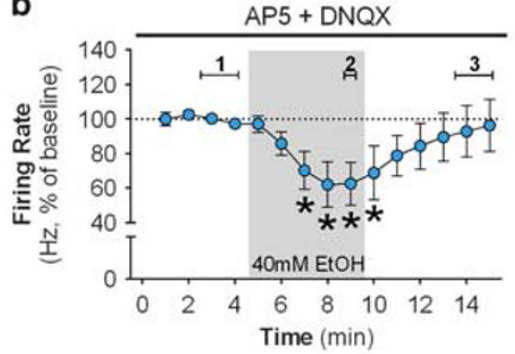

C

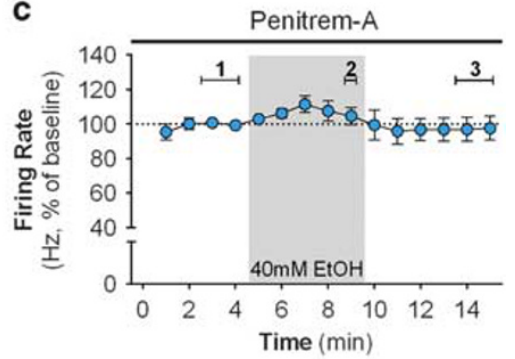

d

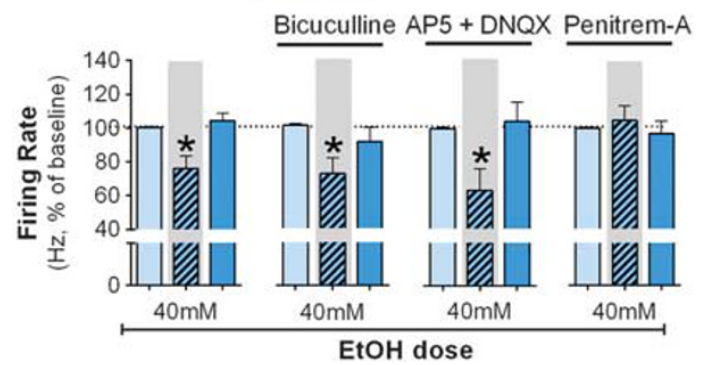

e

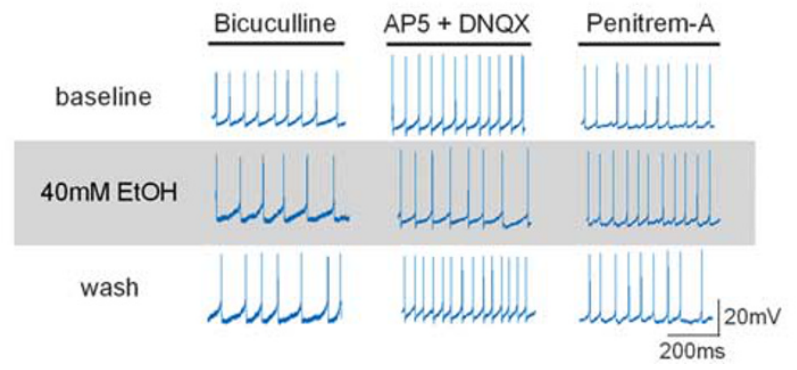

Figure 2 BK channels rather than GABA or glutamatergic synaptic input are necessary for the ethanol-induced decrease in firing. (a) Time course of firing rate of low-frequency GPe neurons ( $n=9$ neurons from 5 mice) in the presence of $20 \mu M$ bicuculline $\left(G_{A B A}\right.$ antagonist; $F_{(14,1 / 2)}=2.37$; * $p<0.05$, post hoc test indicates lower firing rate in minutes $8-10$ when compared with minutes $2-4)$. Inclusion of bicuculline does not eliminate the ethanol-induced decrease in the firing rate $(* p<0.05)$. (b) Time course of firing rate of low-frequency neurons $(n=7$ neurons from 5 mice) in the presence of $50 \mu M$ AP5 and $10 \mu M$ DNQX (glutamatergic NMDA and AMPA antagonists, respectively; $F_{(14.84)}=2.57$; $* 2<0.05$, post hoc test indicates lower firing rate in minutes 7-10 when compared with minutes 1-5). Glutamatergic antagonists did not alter the ethanol-induced decrease in firing rate of low-frequency neurons $(* p<0.05)$. (c) Time course of firing rate of low-frequency neurons ( $n=1$ I neurons from 7 mice) in the presence of a BK channel inhibitor, $500 \mathrm{nM}$ penitrem$A\left(F_{(14,140)}=1\right.$. I2). BK channel inhibition blocks the ethanol-induced decrease in firing of low-frequency neurons. (d) Summary bar graph of low-frequency neurons during baseline, ethanol, and washout calculated as average from time segments I, 2, and 3 indicated in time-course graphs $* 0<0.05$. (e) Representative traces of low-frequency neurons during baseline, $40 \mathrm{mM}$ ethanol, and washout in the presence of bicuculline, AP5+DNQX, or penitrem-A. Firing rate in time courses and bar graphs are represented as percentage of the baseline levels. All error bars represent SEM.

\section{RESULTS}

\section{In Vitro Ethanol Effects on GPe Neurons of C57BL/6J Mice}

Whole-cell patch-clamp recordings were performed in five GPe neurons without any drug application to determine the stability of firing rate under our recording conditions. We observed stable firing rate throughout current-clamp recordings, with a slight increase in the firing rate during minutes $18-20\left(\mathrm{~F}_{(18,72)}=2.05 ; p<0.05\right.$; time course-data not shown, bar graph in Figure 1g). No significant decrease in firing rate was observed during bath application of $10 \mathrm{mM}$ ethanol when averaging the data of the total population of GPe neurons $(n=11)$. However, application of $40 \mathrm{mM}(n=16)$ or $80 \mathrm{mM}(n=13)$ ethanol induced a significant decrease in firing of GPe neurons (Figure 1a). The firing rate rapidly returned to baseline levels after ethanol was washed from the bath.

Subpopulations of GPe neurons differ in several electrophysiological properties (Dodson et al, 2015; Hernandez et al, 2015; Mastro et al, 2014). We observed a large range of firing rates in neurons recorded from C57BL/6J mice $(1-120 \mathrm{~Hz})$ that can be clustered above or below $30-40 \mathrm{~Hz}$ (data not shown). In addition, closer examination of the data from individual neurons indicated that the largest ethanolinduced decreases in firing rate were observed in neurons that had average $<30 \mathrm{~Hz}$ basal firing rates (Figure $1 \mathrm{~b}$ and $\mathrm{c}$ ). Thus, we classified the neurons from C57BL/6J mice as low frequency (firing rate $<30 \mathrm{~Hz}$ ) and high frequency (firing rate $>30 \mathrm{~Hz}$ ). Ethanol significantly decreased the firing of low-frequency neurons (Figure $1 \mathrm{~d}-\mathrm{f}$ ). Although in vitro studies generally use high ethanol concentrations (between 40 and $100 \mathrm{mM}$ ), it is difficult to reach these levels in awake individuals without severe intoxication in non-dependent subjects. Thus, we also examined the effect of $10 \mathrm{mM}$ ethanol, a concentration lower than the legal intoxication level (blood ethanol concentration of $0.08 \mathrm{~g} / \mathrm{dl}$, or $\sim 17 \mathrm{mM}$ in humans). Ethanol $(10 \mathrm{mM})$ decreased the firing rate specifically in low-frequency neurons (Figure 1g: $\left.\mathrm{F}_{(2,12)}=4.36, p<0.05\right)$. Higher concentrations decreased the firing of low-frequency neurons in a dose-dependent manner (Figure 1g, low frequency: $40 \mathrm{mM}: \mathrm{F}_{(2,16)}=7.48, p<0.05$; $\left.80 \mathrm{mM}: \mathrm{F}_{(2,16)}=13.06, p<0.05\right)$. However, ethanol did not change the firing of high-frequency neurons even at high concentrations (Figure 1g, high-frequency neurons: $10 \mathrm{mM}$ : $\left.\mathrm{F}_{(2,6)}=1.09 ; 40 \mathrm{mM}: \mathrm{F}_{(2,12)}=1.80 ; 80 \mathrm{mM}: \mathrm{F}_{(2,6)}=0.14\right)$. It is important to note that $40 \mathrm{mM}$ ethanol specifically increased the inter-spike interval in low-frequency neurons $\left(\mathrm{F}_{(2,16)}=6.71, p<0.05\right)$, but did not affect other measures, such as sag ratio, input resistance, action potential width, and action potential threshold (Supplementary Figure S1).

\section{Ethanol-Induced Decreased Firing Rate Depends on BK Channels}

Molecular and pharmacological evidence supports the effect of ethanol on glutamatergic NMDA receptors and $\mathrm{GABA}_{\mathrm{A}}$ 

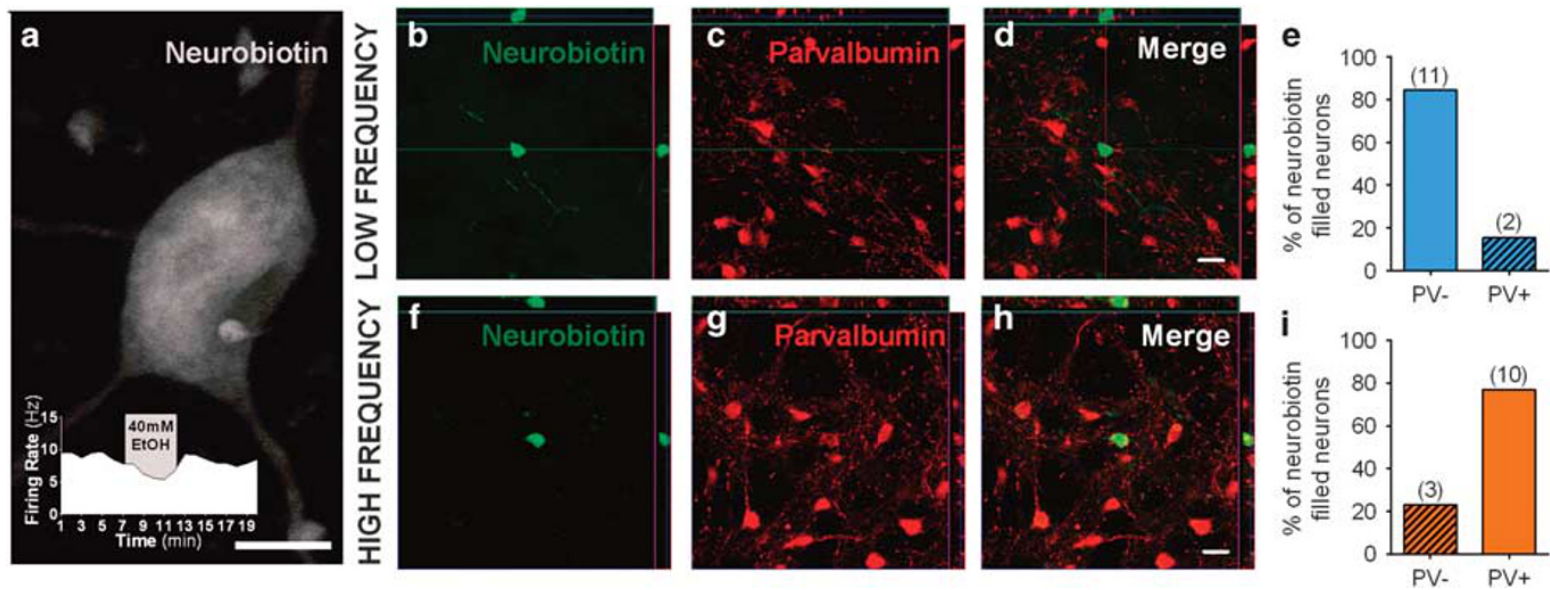

Figure 3 The majority of GPe low-frequency ethanol-sensitive neurons do not express parvalbumin. Neurons were filled with neurobiotin during recordings for post hoc analysis. (a) Example of a filled ethanol-sensitive neuron. Scale bar, $10 \mu \mathrm{m}$. Inset shows the firing rate and ethanol effect on this specific neuron. Thirteen low-frequency and 13 high-frequency neurons were recovered for confocal imaging. (b-d) Confocal and orthogonal sections of a lowfrequency ethanol-sensitive neuron showing no co-localization of neurobiotin (green) and PV staining (red). (e) Bar graph showing the percentage of all labeled low-frequency neurons that express $(\sim 15 \%, n=2)$ or not $(\sim 85 \%, n=1 \mathrm{I})$ the PV protein. $(\mathrm{f}-\mathrm{h})$ Confocal and orthogonal sections of a high-frequency neuron showing co-localization of neurobiotin (green) and PV staining (red). (i) Bar graph showing the percentage of all labeled high-frequency neurons that express $(\sim 77 \%, n=10)$ or not $(\sim 23 \%, n=3)$ the PV protein. Scale bars, $20 \mu \mathrm{m}$.

receptors (Lovinger et al, 1990; Mihic et al, 1997). GPe neurons receive major GABAergic innervation from the striatum and glutamatergic innervation from the STN. We examined the effect of blocking these receptors on ethanol actions in the low-frequency GPe neurons. Application of the GABA $_{\mathrm{A}}$ antagonist bicuculline $(20 \mu \mathrm{M})$ in the absence of ethanol had no effect on the firing rate of low-frequency neurons ( $n=16$ neurons from 9 mice; Student's $t$-test $\mathrm{t}_{(15)}=0.37$, baseline: $\quad 16.24 \pm 2.23 \mathrm{~Hz}$, bicuculline: $18.07 \pm 3.33 \mathrm{~Hz}$ ). Likewise, no significant change in the baseline firing rate was observed in the presence of ionotropic glutamatergic antagonists $(n=11$ neurons from 9 mice; $t_{(11)}=0.28$, baseline: $\quad 11.92 \pm 2.26 \mathrm{~Hz}, \quad$ AP5+DNQX: $12.09 \pm 2.60 \mathrm{~Hz}$ ). The ethanol-induced decrease in firing rate of low-frequency neurons was not blocked by bicuculline (Figure 2a) or the glutamatergic antagonists (Figure 2b). It is important to note that the ethanol effect was similar when experiments were performed with or without $\mathrm{GABA}_{\mathrm{A}}$ and ionotropic glutamatergic antagonists (Figure 2d: bicuculline: $\mathrm{F}_{(2,16)}=5.30, p<0.05 ;$ AP5+DNQX: $\left.\mathrm{F}_{(2,12)}=5.90, p<0.05\right)$. No ethanol effect on high-frequency neurons was observed when experiments were performed in the presence of the antagonists (Supplementary Figure S2).

We concluded that the inhibitory effect of ethanol on GPe firing is not dependent on fast synaptic transmission, so it was possible that this effect was mediated by changes in specific channels involved in the intrinsic control of the GPe neurons pacemaker activity. The BK channels have an important role in controlling firing rate activity $(\mathrm{Gu}$ et al, 2007; Womack et al, 2009) and they are expressed in several brain regions including the GPe (Sausbier et al, 2006; Song et al, 2010). It is known that the BK channel is a molecular target for ethanol (Bukiya et al, 2014). We thus examined the effect of $40 \mathrm{mM}$ ethanol on the firing rate of low-frequency GPe neurons in the presence of a selective BK channel inhibitor, penitrem-A (500 nM). BK channel inhibition alone produced a slight increase in the firing rate of low-frequency neurons $\left(t_{(10)}=2.32, p=0.043\right.$, baseline $15.80 \pm 2.99 \mathrm{~Hz}$, in
penitrem-A $19.67 \pm 3.78 \mathrm{~Hz}$ ). In the presence of penitrem-A, ethanol was no longer able to decrease the firing rate of GPe low-frequency neurons (Figure $2 \mathrm{c}-\mathrm{e}, \mathrm{F}_{(2,20)}=0.68$ ). These data indicate that the $\mathrm{BK}$ channel has a key role in the ethanol-induced decrease in spontaneous activity of GPe low-frequency neurons.

\section{Identifying the Ethanol-Sensitive GPe Neurons}

Neurons examined in the experiments described above were recorded with an internal solution containing neurobiotin, and the slices were immunostained for parvalbumin (PV), a calcium binding protein enriched in high-frequency firing GPe neurons (Abdi et al, 2015; Hernandez et al, 2015; Mastro et al, 2014). We were able to confidently recover 26 neurobiotin-filled neurons out of 67 slices. Figure 3a shows an example of an ethanol-sensitive low-frequency neurobiotin-filled GPe neuron and the time course of firing in this individual neuron before, during and after $40 \mathrm{mM}$ ethanol bath application. Of the recovered neurons, $77 \%$ of the ethanol-insensitive high-frequency neurons were PV positive (10 out of 13 ) and $85 \%$ of ethanol-sensitive lowfrequency neurons were PV negative (11 out of 13; Figure 3). This indicated that ethanol-sensitive low-frequency GPe neurons predominantly do not express PV protein.

Next, we used transgenic mice that express fluorescent markers in subsets of neurons, which allowed us to identify low-frequency firing neurons in living tissue, and target them for in vitro recordings. Although there is a debate about how much overlap of Lhx6 with PV expression occurs in GPe neurons (Abdi et al, 2015; Dodson et al, 2015; Hernandez et al, 2015; Mastro et al, 2014), previous reports indicated that strong GFP expression in the Lhx6-EGFP mouse marks neurons in the GPe with lower-frequency firing rate relative to PV-positive neurons (Hernandez et al, 2015; Mastro et al, 2014). Lhx6-EGFP mice express GFP in several neurons in the brain, including the GPe (Supplementary Figure S3). We found that the firing rate of the Lhx6-EGFP neurons ranged 
a

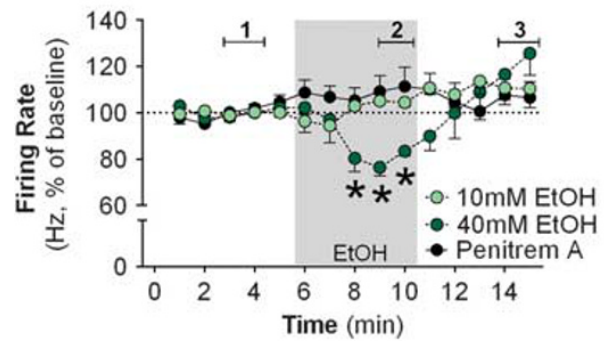

b

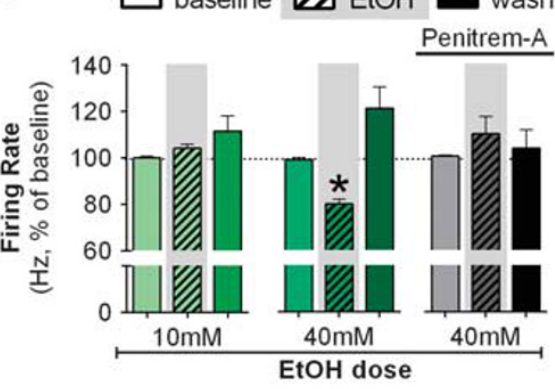

C

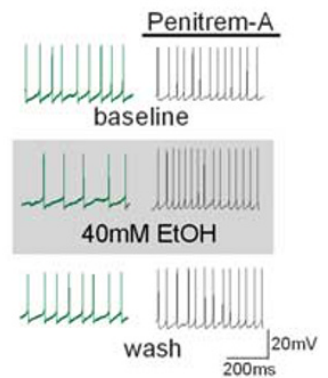

Figure 4 Lhx6 marks a subpopulation of ethanol-sensitive neurons in the GPe. (a) Time course of firing rate of Lhx6-positive neurons during the application of $10 \mathrm{mM}$ ethanol $\left(n=6\right.$ neurons from 5 mice, $F_{(14,70)}=2.29, p<0.05$, post hoc test indicates no difference between minutes 8 and 10 when compared with minutes I-5), $40 \mathrm{mM}$ ethanol ( $n=8$ neurons from 5 mice, $F_{(14,98)}=5.63, p<0.05$, post hoc test indicates lower firing rate in minutes $8-10$ when compared with minutes I-5), and $40 \mathrm{mM}$ ethanol in the presence of $500 \mathrm{nM}$ penitrem-A (BK channel inhibitor, $n=5$ neurons from 2 mice, $F_{(14,56)}=1.1 \mathrm{I}$ ). Application of $40 \mathrm{mM}$ ethanol decreased the firing rate of Lhx6-positive neurons $(* p<0.05)$. (b) Summary bar graph of low-frequency neurons during baseline, ethanol, and washout calculated as average from time segments I, 2, and 3 indicated in time-course graph. Lh×6 neurons are sensitive to $40 \mathrm{mM}$ ethanol (*p <0.05) but not $10 \mathrm{mM}$. Inclusion of the BK channel blocker eliminated the ethanol-induced decrease in firing rate of Lh×6-positive neurons. (c) Representative traces of Lh×6 neurons during baseline, $40 \mathrm{mM}$ ethanol, and washout. Firing rate in time courses and bar graphs are represented as percentage of the baseline levels. All error bars represent SEM.

from 6.0 to $28.3 \mathrm{~Hz}(14.6 \pm 6.0 \mathrm{~Hz}, n=19$ neurons from 12 mice), the range that had signaled ethanol sensitivity in C57BL/6J mice. Time-course graphs are shown in Figure 4a. Although $10 \mathrm{mM}$ ethanol did not have an effect on the firing rate of Lhx6-EGFP neurons (Figure $4 \mathrm{~b}, \mathrm{~F}_{(2,10)}=2.10$ ), $40 \mathrm{mM}$ ethanol induced a reversible inhibition of the Lhx6-EGFP neurons (Figure $4 \mathrm{~b}$ and $c, \mathrm{~F}_{(2,14)}=15.25, p<0.05$ ). This effect was blocked by penitrem-A (Figure $4 \mathrm{a}-\mathrm{c}$ ).

The transcription factor, Npas1, has also been proposed as a marker of low-frequency firing GPe neurons that lack PV expression (Hernandez et al, 2015). Thus, we used a recently developed Npas1-tdTm to examine ethanol effects on firing rate of these neurons in mouse GPe slices. Npas1-tdTm is expressed in several brain regions, including the GPe (Supplementary Figure S3). Npas1-positive neurons exhibited firing rates ranging from 6.3 to $29.6 \mathrm{~Hz}(16.3 \pm 6.5 \mathrm{~Hz}$, $n=23$ neurons from 19 mice), the range that had signaled ethanol sensitivity in the C57BL/6J mice. Time-course graphs are shown in Figure 5a. Ethanol decreased the firing rate of Npas1 neurons (Figure $5 \mathrm{~b}$ and c, $10 \mathrm{mM}: \mathrm{F}_{(2,10)}=9.59$, $\left.p<0.05 ; 40 \mathrm{mM}: \mathrm{F}_{(2,8)}=9.13, p<0.05\right)$ in a dose-dependent manner. Note that Npas1 neurons were affected by the low ethanol concentration, indicating that Npas1 neurons may be more sensitive to ethanol than Lhx6 neurons. Penitrem-A blocked the ethanol effect on Npas1 neurons (Figure $5 \mathrm{~b}$ and c: $\left.F_{(2,8)}=0.41\right)$. To further investigate the dependence of the ethanol effect on BK activity in Npas1 neurons, we also performed the experiment in the presence of paxilline, another BK inhibitor. Again, ethanol was not able to decrease the firing rate of Npas1 neurons when paxilline was present (Figure 5b: $\mathrm{F}_{(2,10)}=0.53$ ), indicating that BK channel activity is necessary for ethanol-induced decreases in firing.

\section{Ethanol Increases BK Channel Open Probability}

We hypothesized that ethanol may potentiate BK function in Npas1 GPe neurons by increasing its open probability. To test this hypothesis, we performed cell-attached singlechannel recordings of BK channel from somata of Npas1 neurons. We were able to find large-conductance channels in $\sim 10 \%$ of the neurons in which we obtained $>4$ GOhm seals.
As an initial control, five BK-positive cell-attached patches were recorded with no drug application over the time frame used for our later pharmacological experiments, and open channel probability $\left(\mathrm{NP}_{\mathrm{o}}\right)$ was stable during these recordings (Figure 5d: $\left.t_{(5)}=0.07\right)$. Penitrem-A $(3 \mu \mathrm{M})$ or paxilline $(3 \mu \mathrm{M})$ was used to assure the recordings that were from BK channels. In the first experiment, we applied the BK antagonist followed by $40 \mathrm{mM}$ ethanol. The antagonists significantly decreased the open probability of the BK channel (Figure 5e: $t_{(5)}=71.68$, $p<0.05)$, which was not changed by the bath application of ethanol (Figure 5e: $t_{(4)}=0.60$ ). Next, we recorded separate patches where $40 \mathrm{mM}$ ethanol was applied followed by the BK inhibitor. In this case, ethanol increased the $\mathrm{BK}$ channel $\mathrm{NP}_{\mathrm{o}}$ (Figure 5 f and i: $t_{(6)}=4.78, p<0.05$ ), which was blocked by the BK inhibitor as expected (Figure $5 f$ and i: $t_{(6)}=3.36, p<0.05$ ). The increase in open probability was driven by an increase in the frequency of the BK channel opening events (Figure 5g: $\left.t_{(6)}=2.42, p<0.05\right)$, but not in the average channel open dwell time (Figure 5h: $t_{(6)}=0.40$ ).

\section{Ethanol Decreases Firing in Low-Frequency GPe Neurons In Vivo}

Having established the ethanol effect on GPe neurons in an in vitro preparation, we sought to define whether such an effect could occur in vivo. We performed in vivo GPe recordings in an open field (Figure 6a). Past studies showed that GPe neuronal firing can be altered by electromyographically recorded movement (Dodson et al, 2015). To minimize changes in locomotion and its influence on neuronal activity, we injected a relatively low ethanol dose $(1 \mathrm{~g} / \mathrm{kg}$ ) that produces $\sim 12 \mathrm{mM}$ brain ethanol concentration $5 \mathrm{~min}$ after the injection (Jamal et al, 2016). We examined effects only after habituation to the open field environment and headstage attachment. Thus, we did not observe a difference in movement speed after saline or ethanol administration ( $t$-test for dependent sample: $t_{(4)}=0.60$, after saline $0.27 \pm 0.10 \mathrm{~cm} / \mathrm{s}$, after ethanol $0.32 \pm 0.60 \mathrm{~cm} / \mathrm{s}$ ).

Twenty-one single units from four mice were included in this analysis. A representative image showing histological verification of electrode array placement is shown in 
a

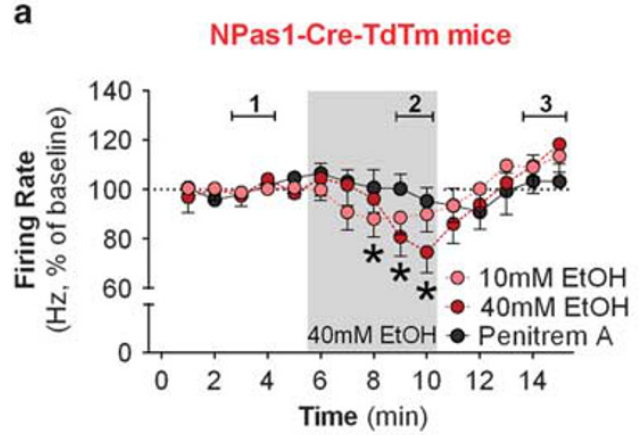

b

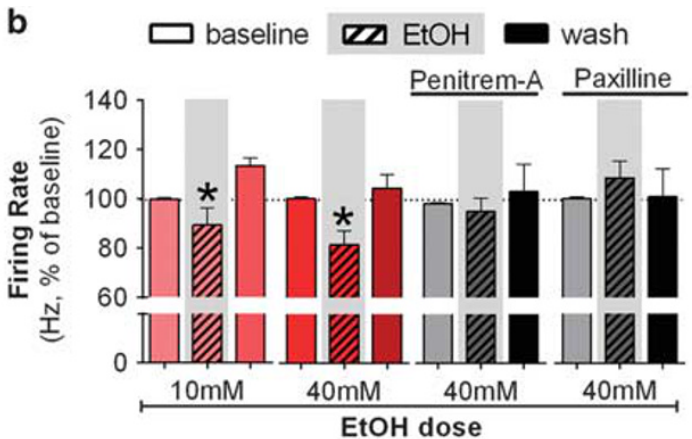

C

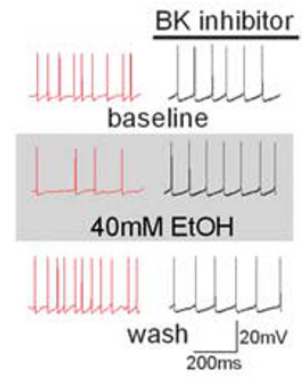

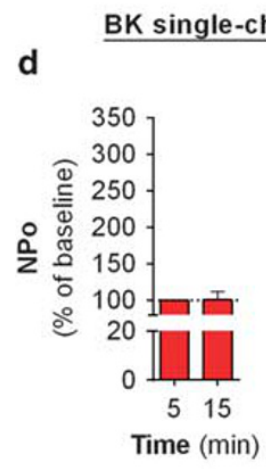
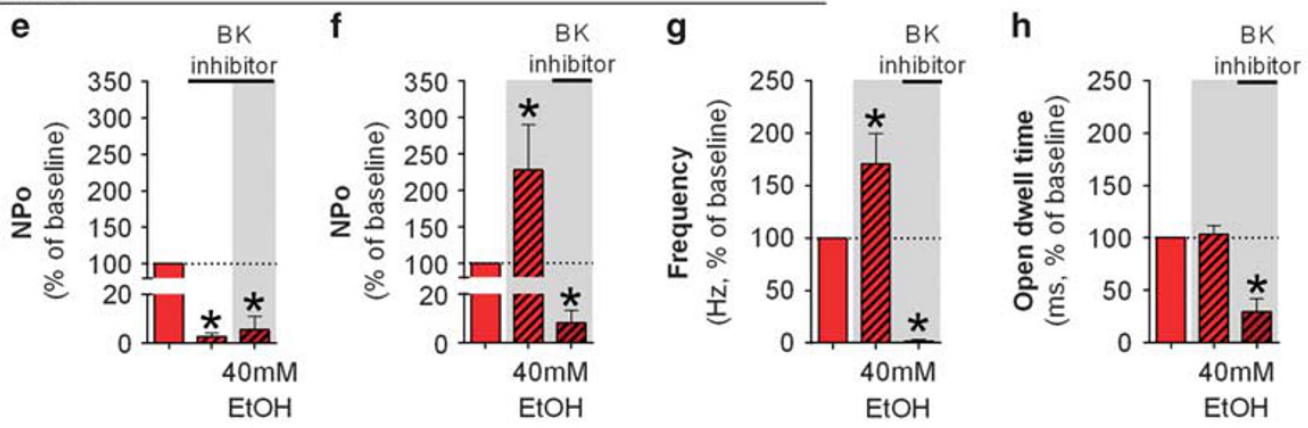

i
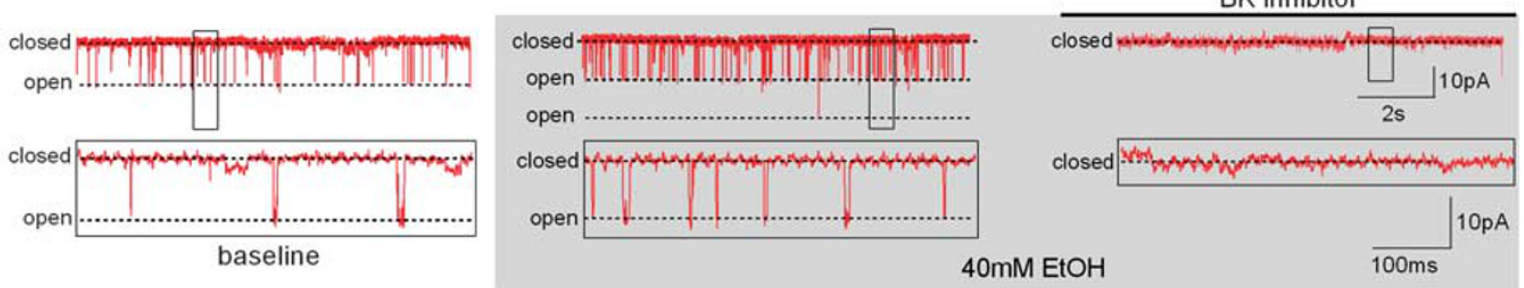

Figure $5 \mathrm{Npas}$ I marks a subpopulation of ethanol-sensitive neurons in the GPe which express ethanol-sensitive BK channels. (a) Time course of firing rate of Npas I-Cre-TdTm-positive neurons during the application of $10 \mathrm{mM}$ ethanol $\left(n=6\right.$ neurons from 6 mice, $F_{(14,70)}=3.70, p<0.05$, post hoc test indicates lower firing rate in minutes $8-9$ when compared with minutes $I-2$ and $4-5), 40 \mathrm{mM}$ ethanol $\left(n=5\right.$ neurons from 6 mice, $F_{(I 4,70)}=2.4 I$, $p<0.05$, post hoc test indicates lower firing rate in minutes 9-10 when compared with minutes 2-4), and $40 \mathrm{mM}$ ethanol in the presence of $500 \mathrm{nM}$ penitrem-A (BK channel blocker, $n=5$ neurons from 3 mice, $\left.F_{(14,56)}=9.82\right)$. Application of $40 \mathrm{mM}$ ethanol decreased the firing rate of Npasl-positive neurons (* $\left.p<0.05\right)$. (b) Summary bar graph of Npas I neurons during baseline, ethanol, and washout calculated as average from time segments I, 2, and 3 indicated in time-course graph. Ethanol dose-dependently decreased the firing rate of Npas I neurons in GPe $(* p<0.05)$. Either $500 \mathrm{nM}$ penitrem-A or I $\mu M$ paxilline (another BK channel inhibitor, $n=6$ neurons from 4 mice) blocked the ethanol effect. (c) Representative traces of Npas I neurons during baseline, $40 \mathrm{mM}$ ethanol, and washout. Firing rate in time courses and bar graphs are represented as percentage of the baseline levels. (d) Single-channel recordings in a Giga-seal cellattached configuration are stable for $5-20$ min as the open probability ( $\left.N P_{\circ}\right)$ did not change over time ( $n=5$ patches from 5 mice). (e) Graphs showing $N P_{\circ}$ values before and during bath application of $3 \mathrm{uM}$ penitrem-A or paxilline and the subsequenct addition of $40 \mathrm{mM}$ EtOH. The BK inhibitors significantly decreased $N_{\circ}$ ( $n=5$ patches from 4 mice; $\left.* 2<0.05\right)$, and in this condition ethanol had no effect ( $n=4$ patches from 3 mice). ( $f$ Graph showing BK channel $\mathrm{NP}$, before and during bath application of $40 \mathrm{mM}$ ethanol followed by the application of $3 \mu \mathrm{M}$ penitrem-A or paxilline. Application of $40 \mathrm{mM}$ ethanol increased $N_{\circ}$ ( $n=6$ patches of 5 mice; * $\left.p<0.05\right)$, which was then inhibited by subsequent application of the BK inhibitor $(n=6$ patches of 4 mice; * $p<0.05)$. (g) Graph showing the frequency of opening transitions before and during bath application of $40 \mathrm{mM}$ ethanol followed by the application of $3 \mu \mathrm{M}$ penitrem-A or paxilline. The increase in $\mathrm{NP}_{\circ}$ induced by ethanol is driven by an increase in the frequency of opening transitions of BK channels. (h) Graph showing open dwell time before and during bath application of $40 \mathrm{mM}$ ethanol followed by the application of $3 \mu \mathrm{M}$ penitrem-A or paxilline. No change in dwell time of BK channel was observed after ethanol application. (i) Example traces showing single-channel recordings. Trace in the bottom of the panel is expanded on the time and current axes relative to those above. All error bars represent SEM.

Figure 6b. Time-course data for unit firing frequency before and after saline or $1 \mathrm{~g} / \mathrm{kg}$ ethanol administration can be observed in Figure 6c. When the firing of all units was averaged, no strong difference in firing rate was observed after saline or ethanol i.p. administration. We classified the single units as low and high frequency using the same criteria used for slice recordings, as the range of firing of GPe neurons in our experiments was similar between in vitro and in vivo preparations (Figure 6d). Fifteen single units were considered low frequency and six were considered high frequency. The large majority of ethanol-inhibited units were low-frequency firing units. Low-frequency units show a significant decrease of $29.6 \pm 12.8 \%$ in firing after ethanol administration compared with saline (simple sample $t$-test, $\left.t_{(15)}=-2.31, p<0.05\right)$. On the other hand, high-frequency units do not show a change in firing after ethanol $\left(-1.65 \pm 14.19 \%\right.$, simple sample $t$-test, $\left.t_{(6)}=-0.12\right)$. As in the in vitro experiments, not all low-frequency neurons were 
a

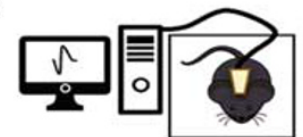
Habituation (1hour)

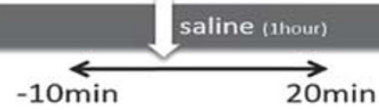
$1 \mathrm{~g} / \mathrm{kg}$ EtOH (1hour)

b

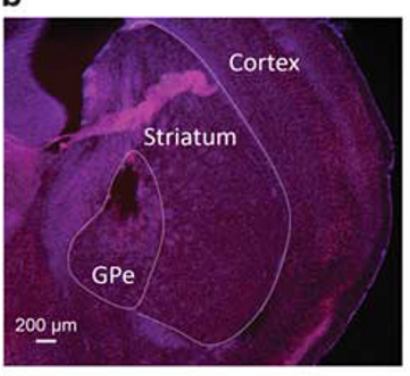

c

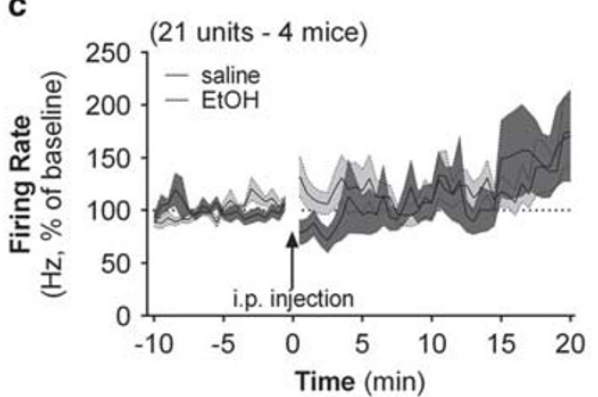

f
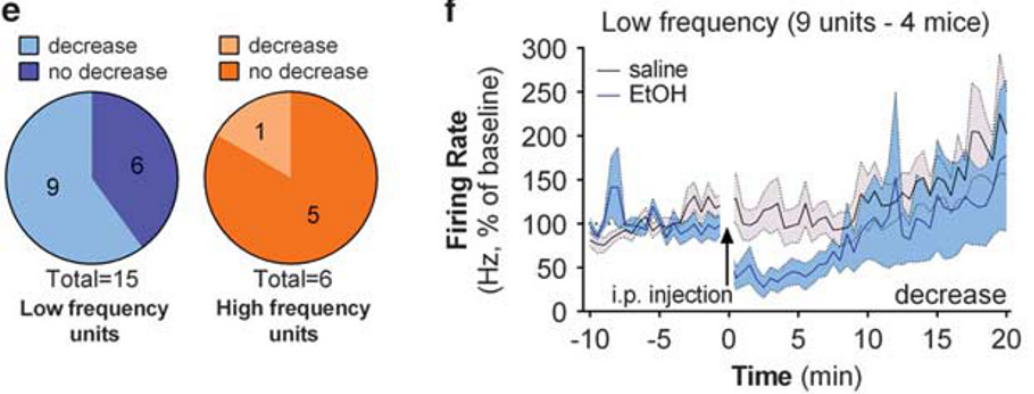

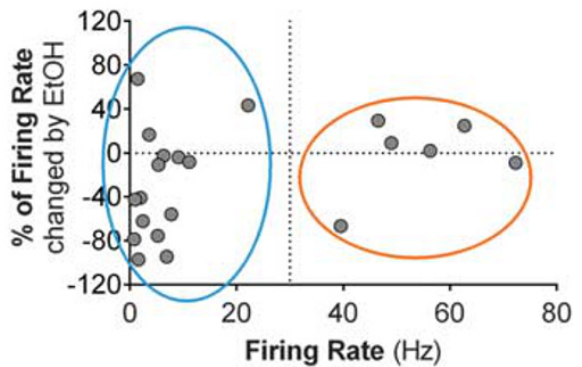

g

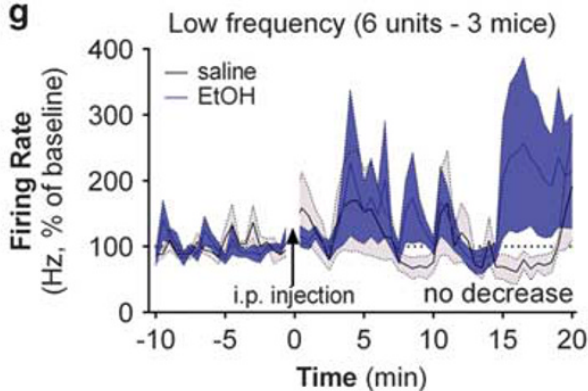

h

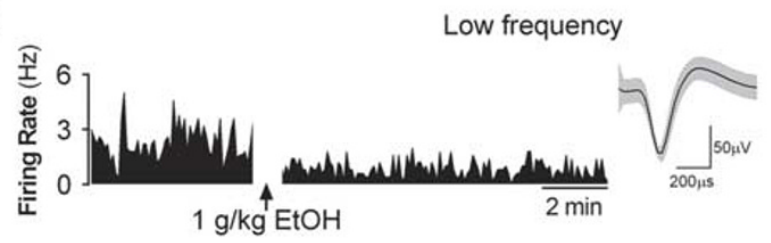

i

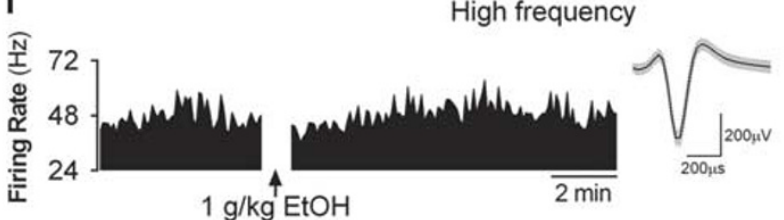

Figure 6 Ethanol decreases the firing rate of a subpopulation of GPe low-frequency neurons in vivo. (a) Experimental design for single unit in vivo recording in freely moving mice. Saline and ethanol administration was counterbalanced to avoid order effects. (b) Representative image of a section of GPe showing the location of the electrodes. (c) Time course of firing rate of all single units recorded from four mice, before and after saline or I g/kg ethanol i.p. administration. (d) Scatterplot of the percent change in firing rate for all single units induced by ethanol compared with saline injections and the baseline firing rate (calculated as the average firing during the I-h habituation). Color-coded marks show neurons classified as low frequency in blue $(<30 \mathrm{~Hz})$ and high frequency in orange $(>30 \mathrm{~Hz})$. Note that ethanol decreased the firing rate of a subpopulation of low-frequency units but did not decrease the firing rate of the majority of highfrequency units. (e) Among the units classified as high-frequency (in orange), only one exhibited a decrease in firing rate $>10 \%$ following ethanol administration in comparison with the saline condition. Among the units classified as low-frequency, $9(60 \%)$ showed an ethanol-induced decrease in firing rate of $>10 \%$. (f) Time course of firing rate of low-frequency single units that were decreased by ethanol. (g) Time course of firing rate of low-frequency single units that did not show an ethanol-induced decrease in firing rate. (h) Histogram showing firing rate during 5 min of baseline and 10 min after ethanol i.p. administration of an ethanol-sensitive low-frequency unit and trace example. (i) Histogram showing firing rate during 5 min baseline and 10 min after ethanol i. p. administration of a typical high-frequency unit and trace example.

affected by ethanol. The decrease in firing appears to be driven by a subpopulation of low-frequency units (defined using the $10 \%$ change from baseline criterion as described in the data analysis section of the Methods). Among the units classified as low frequency, nine (60\%) showed a decreased firing rate following ethanol administration (Figure 6e). Among the units classified in the high-frequency rate category, just one showed an ethanol-induced decrease in firing rate (Figure 6e; Supplementary Figure S4). The ethanol-inhibited low-frequency firing neurons exhibited a rapid decrease in firing that recovered to baseline levels within $10 \mathrm{~min}$ of drug application (Figure 6f). In contrast, the remainder of the low-frequency neurons showed no change in firing rate over the entire $20 \mathrm{~min}$ time course following ethanol exposure (Figure 6g).

\section{DISCUSSION}

Here we describe a selective ethanol inhibition of a specific subpopulation of pacemaker neurons in the GPe. This study provides in vitro and in vivo evidence that ethanol induces a decrease in firing of low-frequency neurons in the GPe. This effect is dependent on the intrinsic properties of the neurons, as it is not blocked by GABAergic or glutamatergic antagonists, but by a BK channel inhibitor. We also identified these cells as low-frequency firing rate neurons that mostly do not express the PV protein. The use of two transgenic mouse lines allowed us to identify ethanol-sensitive neurons, namely, the Lhx6- and Npas1-positive cells. We showed that ethanol increases the open probability of BK channels in Npas1 neurons. On the basis of these findings, we propose that 
within the GPe, ethanol has an effect on specific subpopulations of cells, what we will call ethanol-sensitive neurons.

Most of the studies analyzing neuronal effects of acute in vitro ethanol have been made on neurons with strongly hyperpolarized membrane resting potentials that are only active upon recruitment of excitatory synaptic inputs. However, ethanol effects on spontaneously active neurons have been observed in some brain regions (Brodie et al, 1990; Gessa et al, 1985; Koyama et al, 2007; Okamoto et al, 2006; Shefner and Tabakoff, 1985). Ethanol increases the firing frequency of cerebellar neurons (Wadleigh and Valenzuela, 2012) and dopaminergic neurons in the ventral tegmental area (Brodie et al, 1990; Okamoto et al, 2006), suggesting that these effects involve mechanisms that differ from those that underlie the inhibitory effect in the GPe. Inhibition of spontaneous firing was observed in GABA neurons in the substantia nigra (Mereu and Gessa, 1985) and adrenergic neurons of the locus coeruleus (Shefner and Tabakoff, 1985), but little is known about the mechanisms underlying this inhibition.

Previous work indicated that ethanol enhances the rapid inhibitory effects of GABA on firing of a subpopulation of GPe neurons in anesthetized rats (Criswell et al, 1995). However, these neurons were insufficiently characterized to allow for the determination of subtype. Our observation that the ethanol-induced decrease in firing rate is independent of $\mathrm{GABA}_{\mathrm{A}}$ receptor function indicates that we may be examining a different effect from that studied by Criswell and colleagues. For example, although our effect seems to be related to the cell body control of the pacemaker activity, Criswell et al may have seen effects related to changes in GABAergic synapses on other parts of the GPe neurons. Further investigation is needed to integrate the ethanol effect on specific synapses and neuronal subpopulations in GPe.

Immediate early gene (IEG) expression studies indicate the activation of GPe neurons in particular phases of ethanol exposure/withdrawal (Vilpoux et al, 2009). The GPe has increased IEG expression examined hours after acute ethanol exposure or after withdrawal (Chen et al, 2009; Hitzemann and Hitzemann, 1997; Kolodziejska-Akiyama et al, 2005; Kozell et al, 2005; Putzke et al, 1996). This increased IEG expression is somewhat surprising, as it suggests that ethanol increases GPe neuronal activity, in contrast with our findings. There are a number of reasons for this apparent discrepancy. First, IEG expression only provides an indirect measure of neuronal activity. Second, the specific GPe neuronal subtypes affected by ethanol were not identified in these studies. We can also hypothesize that the increased IEG expression may reflect effects that take place subsequent to the initial inhibitory response to ethanol exposure.

Our study is the first to examine the effects of ethanol on GPe neurons in awake, freely moving mice. Our data show that acute systemic administration of ethanol, at a dose that produces modest brain ethanol levels, induces a strong decrease in firing in a population of low-frequency GPe neurons. Interestingly, in humans, ethanol appears to decrease GPe activity, as evidenced by neuroimaging studies in which an oral dose of ethanol dampened the increase of GPe activity during a visual task and induced a slight decrease of GPe activity (Nikolaou et al, 2013). Although we are aware that GPe high-frequency neurons are characterized by interspersed pauses in monkeys (DeLong, 1971; Elias et al,
2007; Noblejas et al, 2015; Schechtman et al, 2015), we observed only occasional pausing behavior in some GPe neurons (data not shown). One reason for this difference may be species, as in rodents it has been reported that a subset of high-frequency neurons showed only occasional brief pauses (Dodson et al, 2015; Mallet et al, 2016).

The BK channel has a key role in the ethanol-mediated changes in the firing rate of GPe low-frequency neurons. It is well known that BK channels are sensitive to ethanol (Bettinger and Davies, 2014; Dopico et al, 2014). Previous work showed that ethanol potentiates BK channel open probability in isolated hypothalamo-hypophyseal neurons and nucleus accumbens slices (Dopico et al, 1996; Martin et al, 2004; Pietrzykowski et al, 2004). Thus, it is likely that the channels on GPe low-frequency neurons will be affected by this interaction, as suggested by our single-channel data. Interestingly, ethanol potentiates $\alpha$ and $\alpha \beta 4 \mathrm{BK}$ channel open probability, but the potentiation of $\alpha$-only containing BK channel develops acute tolerance after $5 \mathrm{~min}$ of ethanol application (Martin et al, 2008; Velazquez-Marrero et al, 2014). This may explain the fast tolerance of the ethanolinduced decrease in firing of low-frequency neurons observed in our in vivo experiment as the GPe displays strong expression of the $\alpha$-subunit (Sausbier et al, 2006), which could be related to behavioral tolerance to ethanol (Treistman and Martin, 2009). Future studies would be necessary to understand this mechanism.

Recent work has shown that the GPe is comprised of different subtypes of GABAergic neurons (Hegeman et al, 2016). We identified subpopulations of neurons in the GPe that are sensitive to ethanol. The majority of the lowfrequency ethanol-sensitive neurons do not express PV. This finding is consistent with the previous studies showing that $\mathrm{PV}$ is a marker for higher firing rate GPe neurons (Abdi et al, 2015; Hernandez et al, 2015; Mastro et al, 2014). Accordingly, low-frequency neurons in the GPe present other biomarkers. Ethanol decreased the firing of Lhx6 neurons that have firing rates comparable to those we observed in ethanol-sensitive neurons from wild-type mice. Recent studies showed that low-frequency neurons are more specifically labeled by Npas1 (Hernandez et al, 2015). Ethanol decreased the firing rate of Npas1 neurons, an effect that was blocked by $\mathrm{BK}$ inhibitors. We also showed that ethanol directly affects the open probability of BK channels by increasing the frequency of opening events in Npas1 neurons. These findings indicate that increased direct ethanol-induced $\mathrm{BK}$ activation decreases the firing rate of these neurons.

Importantly, the Npas1-positive neurons in the GPe were previously identified as the arkypallidal neurons that send projections back to the striatum (Glajch et al, 2016; Hernandez et al, 2015). A recent paper showed that the arkypallidal cells send a stop signal to the striatum (Mallet et al, 2016), indicating that these low-frequency firing neurons suppress imminent actions. We can speculate that the decrease of arkypallidal neuron firing may temporarily alter these 'stop' signals. In combination with other ethanol effects in the striatum (Patton et al, 2016; Wilcox et al, 2014), this action of ethanol may alter striatal computation with potentially strong consequences for acute intoxication and ethanol drinking behavior. Given the role of the basal ganglia in reward-related behaviors, a brief decrease in GPe firing 
may also have a role in reward processing during ethanol exposure.

Our data indicate that ethanol affects a specific population of neurons in a central pacemaker region of the basal ganglia, the GPe. Future studies will need to pay particular attention to differentiating specific ethanol-sensitive neuronal subpopulations within a brain region. We also identified that BK channel activation is important for the ethanol-induced decrease in firing of GPe neurons. Considering the GPe connections with different brain regions, the present data reveal a significant role of the GPe within the circuitry involved in acute ethanol effects that may be important for ethanol intoxication and alcohol use disorders.

\section{FUNDING AND DISCLOSURE}

This study was supported by the Division of Intramural Clinical and Biological Research of the National Institute on Alcohol Abuse and Alcoholism. Dr Karina P Abrahao's fellowship was also supported by the 2014 IBRO John G. Nicholls Research Fellow and the Ciências sem Fronteiras program (Coordenadoria de Aperfeiçoamento de Pessoal de Nível Superior-CAPES 2496/13-5, Brazil). The development of the Npas1-Cre-2A-tdTomato BAC mice by Dr C. Savio Chan's laboratory was supported by NIH grant R01 NS069777 and P50 NS047085. The funders had no role in study design, data collection and analysis, decision to publish, or preparation of the manuscript. The authors declare no conflict of interest.

\section{ACKNOWLEDGMENTS}

We acknowledge Dr Aryn Gittis for providing the Tg(Lhx6EGFP)BP221Gsat mice and Dr Margaret Davis for expert assistance with immunostaining. We also acknowledge Dr Alexxai Kravitz and Dr Danielle Friend for assistance with preliminary investigation of the in vivo effect of ethanol on firing of GPe neurons.

\section{REFERENCES}

Abdi A, Mallet N, Mohamed FY, Sharott A, Dodson PD, Nakamura $\mathrm{KC}$ et al (2015). Prototypic and arkypallidal neurons in the dopamine-intact external globus pallidus. $J$ Neurosci 35: 6667-6688.

Adler A, Katabi S, Finkes I, Israel Z, Prut Y, Bergman H (2012). Temporal convergence of dynamic cell assemblies in the striatopallidal network. J Neurosci 32: 2473-2484.

Albin RL, Young AB, Penney JB (1989). The functional anatomy of basal ganglia disorders. Trends Neurosci 12: 366-375.

Arkadir D, Morris G, Vaadia E, Bergman H (2004). Independent coding of movement direction and reward prediction by single pallidal neurons. J Neurosci 24: 10047-10056.

Bettinger JC, Davies AG (2014). The role of the BK channel in ethanol response behaviors: evidence from model organism and human studies. Front Physiol 5: 346.

Brodie MS, Shefner SA, Dunwiddie TV (1990). Ethanol increases the firing rate of dopamine neurons of the rat ventral tegmental area in vitro. Brain Res 508: 65-69.

Bukiya AN, Kuntamallappanavar G, Edwards J, Singh AK, Shivakumar B, Dopico AM (2014). An alcohol-sensing site in the calcium- and voltage-gated, large conductance potassium (BK) channel. Proc Natl Acad Sci USA 111: 9313-9318.
Chen G, Reilly MT, Kozell LB, Hitzemann R, Buck KJ (2009). Differential activation of limbic circuitry associated with chronic ethanol withdrawal in DBA/2J and C57BL/6J mice. Alcohol 43: 411-420.

Criswell HE, Simson PE, Knapp DJ, Devaud LL, McCown TJ, Duncan GE et al (1995). Effect of zolpidem on gammaaminobutyric acid (GABA)-induced inhibition predicts the interaction of ethanol with GABA on individual neurons in several rat brain regions. J Pharmacol Exp Ther 273: 526-536.

DeLong MR (1971). Activity of pallidal neurons during movement. J Neurophysiol 34: 414-427.

DeLong MR (1990). Primate models of movement disorders of basal ganglia origin. Trends Neurosci 13: 281-285.

Dodson PD, Larvin JT, Duffell JM, Garas FN, Doig NM, Kessaris N et al (2015). Distinct developmental origins manifest in the specialized encoding of movement by adult neurons of the external globus pallidus. Neuron 86: 501-513.

Dopico AM, Bukiya AN, Martin GE (2014). Ethanol modulation of mammalian BK channels in excitable tissues: molecular targets and their possible contribution to alcohol-induced altered behavior. Front Physiol 5: 466.

Dopico AM, Lemos JR, Treistman SN (1996). Ethanol increases the activity of large conductance, $\mathrm{Ca}(2+)$-activated $\mathrm{K}+$ channels in isolated neurohypophysial terminals. Mol Pharmacol 49: 40-48.

Elias S, Joshua M, Goldberg JA, Heimer G, Arkadir D, Morris G et al (2007). Statistical properties of pauses of the high-frequency discharge neurons in the external segment of the globus pallidus. J Neurosci 27: 2525-2538.

Everitt BJ, Robbins TW (2005). Neural systems of reinforcement for drug addiction: from actions to habits to compulsion. Nat Neurosci 8: 1481-1489.

Gdowski MJ, Miller LE, Parrish T, Nenonene EK, Houk JC (2001). Context dependency in the globus pallidus internal segment during targeted arm movements. J Neurophysiol 85: 998-1004.

Gessa GL, Muntoni F, Collu M, Vargiu L, Mereu G (1985). Low doses of ethanol activate dopaminergic neurons in the ventral tegmental area. Brain Res 348: 201-203.

Glajch KE, Kelver DA, Hegeman DJ, Cui Q, Xenias HS, Augustine EC et al (2016). Npas1+ Pallidal Neurons Target Striatal Projection Neurons. J Neurosci 36: 5472-5488.

Gowing LR, Ali RL, Allsop S, Marsden J, Turf EE, West R et al (2015). Global statistics on addictive behaviours: 2014 status report. Addiction 110: 904-919.

$\mathrm{Gu}$ N, Vervaeke K, Storm JF (2007). BK potassium channels facilitate high-frequency firing and cause early spike frequency adaptation in rat CA1 hippocampal pyramidal cells. J Physiol $\mathbf{5 8 0}$ (Pt. 3): 859-882.

Hegeman DJ, Hong ES, Hernandez VM, Chan CS (2016). The external globus pallidus: progress and perspectives. Eur J Neurosci 10: $1239-1265$.

Hernandez VM, Hegeman DJ, Cui Q, Kelver DA, Fiske MP, Glajch KE et al (2015). Parvalbumin+ neurons and Npas1+ neurons are distinct neuron classes in the mouse external globus pallidus. J Neurosci 35: 11830-11847.

Hitzemann B, Hitzemann R (1997). Genetics ethanol and the Fos response: a comparison of the C57BL/6J and DBA/2J inbred mouse strains. Alcohol Clin Exp Res 21: 1497-1507.

Jamal M, Ameno K, Tanaka N, Ito A, Takakura A, Kumihashi M et al (2016). Ethanol and acetaldehyde after intraperitoneal administration to Aldh2-knockout mice-reflection in blood and brain levels. Neurochem Res 41: 1029-1034.

Kolodziejska-Akiyama KM, Cha YM, Jiang Y, Loh HH, Chang SL (2005). Ethanol-induced FOS immunoreactivity in the brain of mu-opioid receptor knockout mice. Drug Alcohol Depend 80: $161-168$

Koyama S, Brodie MS, Appel SB (2007). Ethanol inhibition of $\mathrm{m}$-current and ethanol-induced direct excitation of ventral tegmental area dopamine neurons. J Neurophysiol 97: 1977-1985. 
Kozell LB, Hitzemann R, Buck KJ (2005). Acute alcohol withdrawal is associated with c-Fos expression in the basal ganglia and associated circuitry: $\mathrm{C} 57 \mathrm{BL} / 6 \mathrm{~J}$ and $\mathrm{DBA} / 2 \mathrm{~J}$ inbred mouse strain analyses. Alcohol Clin Exp Res 29: 1939-1948.

Kupferschmidt DA, Cody PA, Lovinger DM, Davis MI (2015). Brain BLAQ: post-hoc thick-section histochemistry for localizing optogenetic constructs in neurons and their distal terminals. Front Neuroanat 9: 6.

Lovinger DM, Roberto M (2013). Synaptic effects induced by alcohol. Curr Top Behav Neurosci 13: 31-86.

Lovinger DM, White G, Weight FF (1990). NMDA receptormediated synaptic excitation selectively inhibited by ethanol in hippocampal slice from adult rat. J Neurosci 10: 1372-1379.

Mallet N, Schmidt R, Leventhal D, Chen F, Amer N, Boraud T et al (2016). Arkypallidal cells send a stop signal to striatum. Neuron 8: 308-316.

Martin G, Puig S, Pietrzykowski A, Zadek P, Emery P, Treistman S (2004). Somatic localization of a specific large-conductance calcium-activated potassium channel subtype controls compartmentalized ethanol sensitivity in the nucleus accumbens. J Neurosci 24: 6563-6572.

Martin GE, Hendrickson LM, Penta KL, Friesen RM, Pietrzykowski AZ, Tapper AR et al (2008). Identification of a BK channel auxiliary protein controlling molecular and behavioral tolerance to alcohol. Proc Natl Acad Sci USA 105: 17543-17548.

Mastro KJ, Bouchard RS, Holt HA, Gittis AH (2014). Transgenic mouse lines subdivide external segment of the globus pallidus (GPe) neurons and reveal distinct GPe output pathways. J Neurosci 34: 2087-2099.

Mereu G, Gessa GL (1985). Low doses of ethanol inhibit the firing of neurons in the substantia nigra, pars reticulata: a GABAergic effect? Brain Res 360: 325-330.

Mihic SJ, Ye Q, Wick MJ, Koltchine VV, Krasowski MD, Finn SE et al (1997). Sites of alcohol and volatile anaesthetic action on GABA(A) and glycine receptors. Nature 389: 385-389.

Nikolaou K, Critchley H, Duka T (2013). Alcohol affects neuronal substrates of response inhibition but not of perceptual processing of stimuli signalling a stop response. PLoS One 8: e76649.

Noblejas MI, Schechtman E, Adler A, Joshua M, Katabi S, Bergman H (2015). Hold your pauses: external globus pallidus neurons respond to behavioural events by decreasing pause activity. Eur J Neurosci 42: 2415-2425.

Okamoto T, Harnett MT, Morikawa H (2006). Hyperpolarizationactivated cation current (Ih) is an ethanol target in midbrain dopamine neurons of mice. J Neurophysiol 95: 619-626.

Patton MH, Roberts BM, Lovinger DM, Mathur BN (2016). Ethanol disinhibits dorsolateral striatal medium spiny neurons through activation of a presynaptic delta opioid receptor. Neuropsychopharmacology 41: 1831-1840.

Pietrzykowski AZ, Martin GE, Puig SI, Knott TK, Lemos JR, Treistman SN (2004). Alcohol tolerance in large-conductance, calcium-activated potassium channels of CNS terminals is intrinsic and includes two components: decreased ethanol potentiation and decreased channel density. J Neurosci 24: 8322-8332.

Putzke J, Spanagel R, Tolle TR, Zieglgansberger W (1996). The anticraving drug acamprosate reduces $c$-fos expression in rats undergoing ethanol withdrawal. Eur J Pharmacol 317: 39-48.

Qiu MH, Chen MC, Wu J, Nelson D, Lu J (2016). Deep brain stimulation in the globus pallidus externa promotes sleep. Neuroscience 322: 115-120.

Qiu MH, Yao QL, Vetrivelan R, Chen MC, Lu J (2014). Nigrostriatal dopamine acting on globus pallidus regulates sleep. Cereb Cortex 26: $1430-1439$.
Sausbier U, Sausbier M, Sailer CA, Arntz C, Knaus HG, Neuhuber W et al (2006). Ca2+ -activated K+ channels of the BK-type in the mouse brain. Histochem Cell Biol 125: $725-741$.

Schechtman E, Adler A, Deffains M, Gabbay H, Katabi S, Mizrahi A et al (2015). Coinciding decreases in discharge rate suggest that spontaneous pauses in firing of external pallidum neurons are network driven. J Neurosci 35: 6744-6751.

Schroll H, Horn A, Groschel C, Brucke C, Lutjens G, Schneider GH et al (2015). Differential contributions of the globus pallidus and ventral thalamus to stimulus-response learning in humans. NeuroImage 122: 233-245.

Shefner SA, Tabakoff B (1985). Basal firing rate of rat locus coeruleus neurons affects sensitivity to ethanol. Alcohol 2: 239-243.

Smith Y, Bevan MD, Shink E, Bolam JP (1998). Microcircuitry of the direct and indirect pathways of the basal ganglia. Neuroscience 86: 353-387.

Song X, Su W, Chen L, Ji JJ (2010). Functional expression of largeconductance $\mathrm{Ca} 2+$-activated potassium channels in lateral globus pallidus neurons. Neuroscience 169: 1548-1556.

Treistman SN, Martin GE (2009). BK Channels: mediators and models for alcohol tolerance. Trends Neurosci 32: 629-637.

Velazquez-Marrero C, Seale GE, Treistman SN, Martin GE (2014). Large conductance voltage- and $\mathrm{Ca} 2+$-gated potassium (BK) channel beta4 subunit influences sensitivity and tolerance to alcohol by altering its response to kinases. J Biol Chem 289: 29261-29272.

Vengeliene V, Bilbao A, Molander A, Spanagel R (2008). Neuropharmacology of alcohol addiction. Br J Pharmacol 154: 299-315.

Vilpoux C, Warnault V, Pierrefiche O, Daoust M, Naassila M (2009). Ethanol-sensitive brain regions in rat and mouse: a cartographic review, using immediate early gene expression. Alcohol Clin Exp Res 33: 945-969.

Wadleigh A, Valenzuela CF (2012). Ethanol increases GABAergic transmission and excitability in cerebellar molecular layer interneurons from GAD67-GFP knock-in mice. Alcohol Alcohol 47: $1-8$.

Wilcox MV, Cuzon Carlson VC, Sherazee N, Sprow GM, Bock R, Thiele TE et al (2014). Repeated binge-like ethanol drinking alters ethanol drinking patterns and depresses striatal GABAergic transmission. Neuropsychopharmacology 39: 579-594.

Womack MD, Hoang C, Khodakhah K (2009). Large conductance calcium-activated potassium channels affect both spontaneous firing and intracellular calcium concentration in cerebellar Purkinje neurons. Neuroscience 162: 989-1000.

Yang X, Criswell HE, Breese GR (2000). Ethanol modulation of gamma-aminobutyric acid (GABA)-mediated inhibition of cerebellar Purkinje neurons: relationship to $\mathrm{GABAb}$ receptor input. Alcohol Clin Exp Res 24: 682-690.

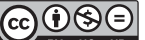

This work is licensed under a Creative Commons Attribution-NonCommercial-NoDerivs 4.0 International License. The images or other third party material in this article are included in the article's Creative Commons license, unless indicated otherwise in the credit line; if the material is not included under the Creative Commons license, users will need to obtain permission from the license holder to reproduce the material. To view a copy of this license, visit http://creativecommons.org/licenses/by-nc-nd/4.0/

(c) The Author(s) 2017

Supplementary Information accompanies the paper on the Neuropsychopharmacology website (http://www.nature.com/npp) 